\section{EFFECTS OF IRON SUPPLEMENTATION ON MORBIDITY, GROWTH, AND AUDITORY BRAINSTEM RESPONSE IN MARGINALLY LBW INFANTS}

\author{
S. Berglund 1 , B. Westrup ${ }^{2}$, E. Haraldsson ${ }^{3}$, \\ B. Engström ${ }^{3}$, M. Domellöf ${ }^{1}$ \\ ${ }^{1}$ Department of Clinical Sciences, Division of \\ Pediatrics, Umeå University, Umeå, ${ }^{2}$ Department \\ of Women and Child Health, Division of \\ Neonatology, Karolinska Institute, ${ }^{3}$ Department of \\ Audiology, Karolinska Hospital, \\ Stockholm, Sweden
}

Background and aims: Low birth weight infants are at risk for iron deficiency, which is associated with poor neurodevelopment. Iron supplements may have adverse effects on growth and morbidity in iron replete infants. Effects of iron supplementation have not been studied in marginally low birth weight infants (MLBW, 2000-2500g). Our objective was to study the effects of iron supplements on auditory brainstem response $(A B R)$, growth and morbidity in MLBW infants.

Methods: In a randomized, controlled trial, 285 healthy MLBW infants received 0,1 , or $2 \mathrm{mg}$ iron/ $\mathrm{kg} / \mathrm{day}$ of iron supplements from six weeks to six months of age. Morbidity was monitored by a daily calendar. Anthropometric data was collected at six weeks and six months. Wave $V$ latency and central conduction time (CCT) were measured using ABR at six months, as markers of neurodevelopment.

Results: There were no significant differences between groups in growth, longitudinal prevalence of morbidity or ABR wave $\mathrm{V}$ latencies. CCT, which was only obtained in 126 infants, was significantly higher in the $2 \mathrm{mg}$ group (4.62 $\mathrm{ms}$ ) than in the placebo group (4.46 ms). However, there were no significant correlations between CCT and iron intake or any of the iron status variables, suggesting that group differences in CCT were not caused by iron.

Conclusions: We conclude that there were no short term functional effects of iron supplementation in this risk group with regard to morbidity, growth or $A B R$ wave $V$ latencies up to six months of age. Long-term health and neurodevelopment will be followed in these children.
173

\section{NEW IRON STATUS PARAMETERS IN PRETERM INFANTS WITH BIRTHWEIGHT < 1500 GRAMS DURING THE FIRST YEAR OF LIFE}

\section{I.K. Torsvik' ${ }^{1}$ P.M. Ueland ${ }^{2,3}$, T. Markestad $^{1}$,} A.-L.B. Monsen ${ }^{3}$

${ }^{1}$ Departments of Pediatrics, Haukeland University Hospital, ${ }^{2}$ Institute of Medicine, University of Bergen, ${ }^{3}$ Departments of Clinical Biochemistry, Haukeland University Hospital, Bergen, Norway

Aims: Preterm birth implies a risk of iron deficiency and anemia. Various parameters have been used to monitor iron status. New parameters include reticulocyte haemoglobin content $(\mathrm{CHr})$, and percentage of microcytic (Micro\%) and hypochromic (Hypo\%) red cells. Various cut-off levels for $\mathrm{CHr}(<$ 26.0 and $<27.5 \mathrm{pg}$ ) for predicting iron deficiency have been suggested in children.

Method: We included 29 preterm infants with birth weight < 1500 grams. Infant hematological and iron parameters; $\mathrm{CHR}$, Micro\%, Hypo\% red cells and serum-ferritin, were recorded at corrected term, 2, 6 and 12 months. According to routine, iron supplementation was recommended from 6 weeks to one year of age.

Results: Mean birth weight was 1063 (SD 300) grams and mean gestational age was 28.5 (SD 2.2) weeks. Haemoglobin level $(\mathrm{Hb})$ and Micro\% increased, while $\mathrm{CHr}$ level and $\mathrm{Hypo} \%$ decreased from corrected term to 12 months. $\mathrm{CHr}$ was negatively correlated to both Micro\% and Hypo\% and positively, but invariably correlated to $\mathrm{Hb}$ during this period. No significant correlations were seen to s-ferritin for $\mathrm{CHr}, \mathrm{Micro} \%$, $\mathrm{Hypo} \%$ and $\mathrm{Hb}$. At 12 months, 6/29 infants had a $\mathrm{CHr}<26 \mathrm{pg}$, and $13 / 29$ infants had a $\mathrm{CHr}<27.5 \mathrm{pg}$. Both values were associated with a lower $\mathrm{Hb}$ level and higher $\mathrm{Hypo} \%$ red cells.

Conclusion: Weobservednosignificantcorrelations between serum-ferritin and $\mathrm{Hb}$ and the new iron parameters in this cohort of preterm infants. $\mathrm{CHr}$ correlated well with $\mathrm{Hb}$, Micro\% and $\mathrm{Hypo} \%$ red cells and may be a better indicator of current iron status than serum-ferritin in preterm infants. 